\title{
Predictive Value of First-Trimester Glycosylated Hemoglobin Levels in Gestational Diabetes Mellitus: A Chinese Population Cohort Study
}

\author{
Jianbin Sun, ${ }^{1}$ Sanbao Chai, ${ }^{1}$ Xin $Z$ Zhao, ${ }^{1}$ Ning Yuan, ${ }^{1}$ Jing Du, ${ }^{1}$ Yufang Liu, ${ }^{1}$ Zhi Li, ${ }^{2}$ \\ and Xiaomei Zhang $\mathbb{1}^{1}$ \\ ${ }^{1}$ Department of Endocrinology and Metabolism, Peking University International Hospital, Beijing 102206, China \\ ${ }^{2}$ Department of Obstetrics and Gynecology, Peking University International Hospital, Beijing 102206, China \\ Correspondence should be addressed to Xiaomei Zhang; z.x.mei@163.com
}

Received 15 January 2021; Revised 9 March 2021; Accepted 18 March 2021; Published 10 April 2021

Academic Editor: Antonio Schiattarella

Copyright (C) 2021 Jianbin Sun et al. This is an open access article distributed under the Creative Commons Attribution License, which permits unrestricted use, distribution, and reproduction in any medium, provided the original work is properly cited.

\begin{abstract}
This study was aimed at exploring the predictive value of first-trimester glycosylated hemoglobin (HbA1c) levels in the diagnosis of gestational diabetes mellitus (GDM). A total of 744 pregnant women registered at the Peking University International Hospital between March 2017 and March 2019 were included in this study. Data on personal characteristics and biochemical indicators of the pregnant women were collected during the first trimester. The International Association of Diabetes and Pregnancy Study Groups has adopted specific diagnostic criteria as the gold standard for the diagnosis of GDM. Receiver operating characteristic (ROC) curve statistics were used to assess the predictive value of first-trimester HbA1c levels in the diagnosis of GDM. HbA1c levels in the first trimester were significantly higher in the GDM group than in the non-GDM group $(5.23 \% \pm 0.29 \%$ vs. $5.06 \pm$ $0.28 \%, P<0.05)$. The first-trimester HbAlc level was an independent risk factor for gestational diabetes. The area under the ROC curve (AUC) of HbA1c for GDM was 0.655 (95\% confidence interval $0.620-0.689, P<0.001$ ). The positive likelihood ratio was the highest at $\mathrm{HbAlc}=5.9 \%$, sensitivity was 2.78 , and specificity was $99.83 \%$. There was no statistical difference in AUC between fasting blood glucose and HbAlc $(P=0.407)$. First-trimester HbAlc levels can be used to predict GDM. The risk of GDM was significantly increased in pregnant women with first-trimester HbAlclevels $>5.9 \%$. There was no statistical difference between first-trimester $\mathrm{HbAlc}$ and fasting blood glucose levels in predicting GDM.
\end{abstract}

\section{Introduction}

Gestational diabetes mellitus (GDM) is defined as abnormal glucose tolerance with onset or first recognition during pregnancy; however, blood glucose levels in cases of GDM do not reach those indicating obvious diabetes mellitus [1]. With the current global coronavirus disease 2019 (COVID-19) pandemic, local lockdowns have induced an unhealthy diet, physical inactivity, and increased psychological stress [2]. That is an even greater challenge for GDM management. Although pregnant women with GDM followed up as usual during the COVID-19 pandemic lockdown, their diabetes control was lower, with a higher rate of insulin therapy [3]. Pregnant women with GDM have an increased risk of developing preeclampsia, increased rates of cesarean sections, and an increased risk of macrosomia [4]. In addition, pregnant women with GDM have a significantly increased risk of developing type 2 diabetes mellitus later in life $[5,6]$. There is a critical period for fetal organ development in the early stages of pregnancy. Abnormal glucose metabolism during this period can result in organ malformation in the developing fetus [7]. Therefore, early screening for GDM is critical. The first-trimester HbAlc level is a reliable predictor of complications during pregnancy, including preeclampsia, fetal macrosomia, and large for gestational age birth weight [8]. Fasting blood glucose (FBG) is used as an early screening tool for gestational diabetes. However, FBG requires fasting, and as FBG has great variability and poor repeatability, it is not effective in the early screening for GDM. Measuring glycosylated hemoglobin (HbAlc) levels has several advantages over 
measuring FBG levels [9]: it is more convenient as fasting is not required and more stable and is subject to fewer day-today variations due to stress or illness. HbA1c has been widely used in the diagnosis and management of diabetes patients, but its use in the diagnosis of gestational diabetes remains controversial as HbAlc levels fall during the first trimester [10]. This study was aimed at exploring the value of firsttrimester HbA1c levels in predicting GDM.

\section{Materials and Methods}

2.1. Participants. This was a prospective cohort study. A total of 744 pregnant women registered at the Peking University International Hospital in China between March 2017 and March 2019 were included in this study. Inclusion criteria were as follows: pregnant women aged 19-45, resident in Beijing for more than 5 years and registered at this hospital, pregnancy confirmed by ultrasound or blood human chorionic gonadotropin test, and available data on first-trimester HbA1c levels. Exclusion criteria were as follows: absence of $\mathrm{HbA} 1 \mathrm{c}$ and routine blood tests in the first trimester; absence of height and/or weight data in the first trimester; a history of prepregnancy diabetes or impaired glucose tolerance; abortion; twin or multiple births; anemia; personal or family history of thyroid disease; use of oral contraceptives or any other drug that may affect thyroid function; and presence of Hashimoto's disease, chronic autoimmune disease malignant tumors, or blood diseases.

The study was approved by the Biomedical Ethics Committee of the Peking University International Hospital (2016-015, 20160710) (2017-021, 20170608). Participants selected for the study gave their informed consent in writing before enrollment.

2.2. Methods. In this study, 744 pregnant women were included for follow-up during pregnancy. All participants underwent blood tests in their first trimester, including evaluation of the red blood cell (RBC) count and hemoglobin (Hb), HbA1c, FBG, triglyceride (TG), total cholesterol (TC), high-density lipoprotein cholesterol, low-density lipoprotein cholesterol, creatinine $(\mathrm{Cr})$, uric acid (UA), thyroid stimulating hormone (TSH), free triiodothyronine (FT3), free thyroxine (FT4), total triiodothyronine (TT3), and total thyroxine (TT4) levels. Gestational age was confirmed on the basis of the self-reported date of the last menstrual period or by ultrasound. The nurse recorded each participant's age, number of deliveries, blood pressure, height, and weight. Participants received routine antenatal care throughout their pregnancies, and all participants were screened for gestational diabetes using a $75 \mathrm{~g}$ oral glucose tolerance test between 24 and 28 weeks of pregnancy.

2.3. Diagnostic Criteria for GDM. GDM was diagnosed using the IADPSG diagnostic criteria [11], which involves a $75 \mathrm{~g}$ oral glucose tolerance test (OGTT). GDM is excluded on the basis of FBG $<5.1 \mathrm{mmol} / \mathrm{l}$, blood glucose 1 hour after glucose load $<10.0 \mathrm{mmol} / \mathrm{l}$, and blood glucose 2 hours after glucose load $<8.5 \mathrm{mmol} / \mathrm{l}$. GDM may be diagnosed if any blood glucose level reaches or exceeds the above limits. These diagnostic criteria were recommended by the American Diabetes Association (ADA) [12] and the Chinese Diabetes Association [13]. The diagnostic criteria for diabetes mellitus were adopted by the World Health Organization in 1999. Prepregnancy diabetes is defined as type 1 diabetes mellitus, type 2 diabetes mellitus, or a special type of diabetes diagnosed before pregnancy.

$\mathrm{HbA1c}$ was detected using a G8 automatic HbA1c analyzer with high-performance liquid chromatography. Thyroid function was determined using the Roche COBASE601 automatic electrochemical luminescence method.

2.4. Statistical Analysis. Data analysis was performed using SPSS 23.0. The Kolmogorov-Smirnov test (K-S test) was used to test the normality of distribution, and measurement data were represented as $\overline{\mathrm{X}} \pm s$. An independent sample $t$ -test was used for comparison between the two groups according to normal distribution. The rank sum test was used to compare the two groups that did not conform to a normal distribution. Categorical variables were analyzed using the $\chi^{2}$ test. Logistic regression analysis was used to analyze the risk factors for GDM. MedCalc statistical software was used to analyze the receiver operating characteristic (ROC) curve of $\mathrm{HbAlc}$ in diagnosing GDM. The areas under the three ROC curves of FBG, HbAlc, the combination of FBG and $\mathrm{HbAlc}$ were compared. Statistical significance was set at $P<0.05$.

\section{Results}

3.1. Comparison of General Clinical Data between the GDM Group and the Non-GDM Group. All 744 participants underwent a $75 \mathrm{~g}$ OGTT during the second trimester. Among them, 144 participants were diagnosed as having GDM, and 600 participants had normal blood glucose levels. The prevalence of GDM was $19.7 \%$. The average age of the participants diagnosed with GDM was higher than that of the participants with normal blood glucose levels $(32.76$ years \pm 3.91 years vs. 30.62 years \pm 3.64 years, $P<0.05)$. First-trimester $\mathrm{HbA1c}$ levels were significantly higher in the GDM group than in the non-GDM group $(5.23 \% \pm 0.29 \%$ vs. $5.06 \% \pm 0.28 \%$, $P<0.05)$. The FBG level in the GDM group was higher than that in the non-GDM group $(5.05 \mathrm{mmol} / \mathrm{l} \pm 0.44 \mathrm{mmol} / \mathrm{l} \mathrm{vs}$. $4.88 \mathrm{mmol} / \mathrm{l} \pm 0.34 \mathrm{mmol} / \mathrm{l}, P<0.05)$. The incidence of gestational diabetes in multiparous participants was $26.4 \%$, which was significantly higher than that in the primiparous participants $(P<0.05)$. Triglyceride, cholesterol, and UA levels in the GDM group were also significantly higher than those in the non-GDM group $(P<0.05)$. There were no statistically significant differences in TSH, TT3, TT4, FT3, FT4, or $\mathrm{Cr}$ between the two groups (Table 1).

3.2. Independent Risk Factors for GDM. As shown in Table 2, logistic regression analysis was performed with GDM as the dependent variable and age; $\mathrm{BMI} \geq 24 \mathrm{~kg} / \mathrm{m}^{2}$ (dichotomous variable); parity; and first-trimester $\mathrm{HbAlc}$, TC, TG, LDLC, HDLC, TSH, TT3, TT4, FT3, and FT4 levels as independent variables. The results showed that age, BMI $\geq 24 \mathrm{~kg} / \mathrm{m}^{2}$, first- 
TABLE 1: Comparison of general clinical data between the GDM group and the NGDM group $(\bar{x} \pm s)$.

\begin{tabular}{|c|c|c|c|}
\hline & GDM & NGDM & $P$ \\
\hline$n$ & $144(19.4 \%)$ & $600(80.6 \%)$ & \\
\hline Age (year) & $32.76 \pm 3.91$ & $30.62 \pm 3.64$ & $<0.05$ \\
\hline Gestational week (weeks) & $8.49 \pm 2.15$ & $8.66 \pm 2.10$ & 0.394 \\
\hline \multicolumn{4}{|l|}{ Parity } \\
\hline Primiparity & $72(15.3 \%)$ & $399(84.7 \%)$ & \multirow[t]{2}{*}{$<0.05$} \\
\hline Multiparity & $72(26.4 \%)$ & $201(73.6 \%)$ & \\
\hline SBP (mmHg) & $109.63 \pm 12.50$ & $109.50 \pm 11.43$ & 0.732 \\
\hline DBP (mmHg) & $66.14 \pm 11.80$ & $65.55 \pm 10.83$ & 0.648 \\
\hline BMI $\left(\mathrm{kg} / \mathrm{m}^{2}\right)$ & $22.32 \pm 2.87$ & $21.63 \pm 2.77$ & $<0.05$ \\
\hline $\mathrm{BMI}<24 \mathrm{~kg} / \mathrm{m}^{2}, \mathrm{n} / \mathrm{N} \%$ & $92(15.6 \%)$ & $497(84.4 \%)$ & \multirow{2}{*}{$<0.05$} \\
\hline $\mathrm{BMI} \geq 24 \mathrm{~kg} / \mathrm{m}^{2}, \mathrm{n} / \mathrm{N} \%$ & $52(33.5 \%)$ & $103(66.5 \%)$ & \\
\hline $\mathrm{HB}(\mathrm{g} / \mathrm{l})$ & $130.92 \pm 8.53$ & $130.74 \pm 10.76$ & 0.785 \\
\hline HbAlc (\%) & $5.23 \pm 0.29$ & $5.06 \pm 0.28$ & $<0.05$ \\
\hline FBG (mmol/l) & $5.05 \pm 0.44$ & $4.88 \pm 0.34$ & $<0.05$ \\
\hline $\mathrm{Cr}(\mathrm{mmol} / \mathrm{l})$ & $48.34 \pm 7.60$ & $48.78 \pm 6.96$ & 0.871 \\
\hline UA (mmol/l) & $266.07 \pm 50.71$ & $213.07 \pm 49.38$ & $<0.05$ \\
\hline $\mathrm{TC}(\mathrm{mmol} / \mathrm{l})$ & $4.09 \pm 0.90$ & $3.93 \pm 0.65$ & $<0.05$ \\
\hline TG (mmol/l) & $1.11 \pm 0.77$ & $0.98 \pm 0.582$ & $<0.05$ \\
\hline LDLC (mmol/l) & $2.12 \pm 0.55$ & $2.04 \pm 0.53$ & 0.155 \\
\hline HDLC (mmol/l) & $1.50 \pm 0.81$ & $1.42 \pm 0.25$ & 0.868 \\
\hline $\mathrm{TSH}(\mu \mathrm{IU} / \mathrm{ml})$ & $1.91 \pm 1.25$ & $2.05 \pm 6.74$ & 0.228 \\
\hline FT4 (pmol/l) & $16.79 \pm 2.27$ & $17.13 \pm 2.96$ & 0.317 \\
\hline FT3 (pmol/l) & $4.71 \pm 0.46$ & $4.77 \pm 1.61$ & 0.822 \\
\hline TT4 (nmol/l) & $122.70 \pm 23.91$ & $121.75 \pm 23.88$ & 0.945 \\
\hline TT3 (nmol/l) & $2.08 \pm 0.40$ & $2.05 \pm 0.45$ & 0.393 \\
\hline \multicolumn{4}{|l|}{ OGTT } \\
\hline $\mathrm{FBG}(\mathrm{mmol} / \mathrm{l})$ & $4.89 \pm 0.55$ & $4.48 \pm 0.36$ & $<0.05$ \\
\hline $1 \mathrm{hBG}(\mathrm{mmol} / \mathrm{l})$ & $9.67 \pm 1.56$ & $7.30 \pm 1.34$ & $<0.05$ \\
\hline $2 \mathrm{hBG}(\mathrm{mmol} / \mathrm{l})$ & $8.40 \pm 1.66$ & $6.64 \pm 0.98$ & $<0.05$ \\
\hline
\end{tabular}

Abbreviations: BMI: body mass index; SBP: systolic blood pressure; DBP: diastolic blood pressure; FBG: fasting blood glucose; HbAlc: glycosylated hemoglobin; Cr: creatinine; UA: uric acid; TC: total cholesterol; TG: triglyceride; LDL-C: low-density lipoprotein cholesterol; HDL-C: highdensity lipoprotein cholesterol; TSH: thyroid stimulating hormone; FT3: free triiodothyronine; FT4: free thyroxine; TT3: total triiodothyronine; TT4: total thyroxine.

trimester $\mathrm{HbAlc}$ level, and FBG level were independent risk factors for GDM.

3.3. ROC Curve of First-Trimester HbA1c Level for Predicting GDM. As shown in Figure 1, the AUC of the first-trimester HbA1c level in the diagnosis of GDM was 0.655 (95\% confidence interval, $0.620-0.689), P<0.001$. When the HbAlc level was $5.3 \%$, the Jorden index was the highest, and the sensitivity and specificity of the diagnosis of GDM were $33.33 \%$ and $89.67 \%$, respectively. When the HbAlc level was 5.9\%, the positive likelihood ratio was the highest at 16.35 , and the sensitivity and specificity for diagnosing GDM were
TABLE 2: Logistic regression analysis of influencing factors of GDM.

\begin{tabular}{lccccc}
\hline & $B$ & SE & $P$ & OR & $95 \%$ CI \\
\hline HbA1c & 1.756 & 0.408 & $<0.05$ & 5.787 & $2.601-12.879$ \\
Age & 0.072 & 0.030 & $<0.05$ & 1.075 & $1.014-1.140$ \\
Parity & 0.311 & 0.221 & 0.159 & 1.364 & $0.885-2.103$ \\
BMI $\geq 24 \mathrm{~kg} / \mathrm{m}^{2}$ & 0.115 & 0.035 & $<0.05$ & 1.122 & $1.047-1.202$ \\
FBG & 0.888 & 0.283 & $<0.05$ & 2.431 & $1.395-4.236$ \\
UA & 0.003 & 0.002 & 0.180 & 1.003 & $0.999-1.007$ \\
TC & 0.144 & 0.149 & 0.334 & 1.155 & $0.862-1.546$ \\
TG & -0.097 & 0.167 & 0.559 & 0.907 & $0.654-1.258$ \\
Constant & -21.19 & 2.52 & $<0.05$ & & \\
\hline
\end{tabular}

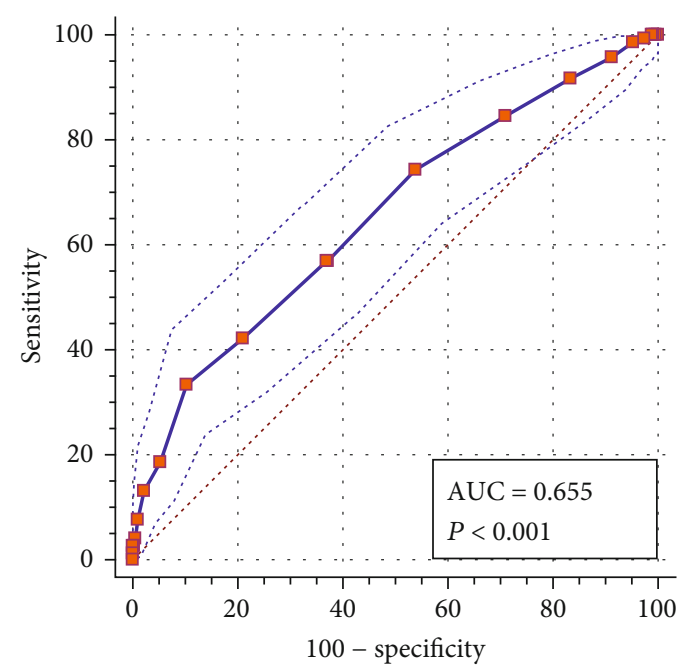

Figure 1: The ROC curve of first-trimester HbA1c level in the diagnosis of GDM in pregnancy.

$2.78 \%$ and $99.83 \%$, respectively. When $\mathrm{HbAlc}$ was $4.4 \%$, the negative likelihood was the lowest, sensitivity was $100 \%$, and specificity was $1.67 \%$, as shown in Table 3 .

3.4. Comparisons between the AUCs of HbAlc and FBG. The AUC of the FBG level for the diagnosis of GDM was 0.625 (95\% confidence interval, $0.589-0.660, P<0.001$ ). There was no statistical difference in the AUCs between FBG and HbAlc levels $(P=0.407)$. The AUC of the combination of FBG and HbAlc levels for the diagnosis GDM was 0.677 (95\% confidence interval, $0.642-0.71, P<0.001$ ). The AUC was not significantly different between the single HbAlc level and the FBG and HbAlc $(P=0.145)$ levels combined, as shown in Figure 2.

\section{Discussion}

GDM may increase adverse outcomes such as hypoglycemia, fetal death, neonatal respiratory distress syndrome, and giant shoulder dystocia $[14,15]$. The rate of cesarean section increases in pregnant women with GDM. The rate of cesarean section does not decrease even when labor is actively induced at 38 weeks' gestation [16]. GDM may increase the risk of type 2 diabetes in both the mother and her child 
TABLE 3: ROC curve values of first-trimester Hbalc in the diagnosis of GDM.

\begin{tabular}{lcccc}
\hline HbA1c & Sensibility $(95 \%$ CI $)$ & Specificity $(95 \%$ CI $)$ & PLR $(95 \%$ CI $)$ & NLR $(95 \%$ CI $)$ \\
\hline$>4.4$ & $100(97.5-100.0)$ & $1.17(0.5-2.4)$ & $1.02(1.0-1.0)$ & 0 \\
$>4.5$ & $99.31(96.2-100.0)$ & $2.67(1.5-4.3)$ & $1.04(1.0-1.1)$ & $0.26(0.03-1.9)$ \\
$>4.6$ & $98.61(95.1-99.8)$ & $4.83(3.3-6.9)$ & $1.05(1.0-1.1)$ & $0.29(0.07-1.2)$ \\
$>4.7$ & $95.83(91.2-98.5)$ & $8.83(6.7-11.4)$ & $1.1(1.0-1.2)$ & $0.47(0.2-1.1)$ \\
$>4.8$ & $91.67(85.9-95.6)$ & $16.67(13.8-19.9)$ & $1.19(1.1-1.3)$ & $0.5(0.3-0.9)$ \\
$>4.9$ & $84.72(77.8-90.2)$ & $29(25.4-32.8)$ & $1.38(1.2-1.6)$ & $0.53(0.4-0.8)$ \\
$>5$ & $74.31(66.4-81.2)$ & $46.17(42.1-50.2)$ & $1.53(1.3-1.8)$ & $0.56(0.4-0.7)$ \\
$>5.1$ & $56.94(48.4-65.2)$ & $62.83(58.8-66.7)$ & $1.54(1.3-1.8)$ & $0.69(0.6-0.8)$ \\
$>5.12$ & $56.94(48.4-65.2)$ & $63(59.0-66.9)$ & $3.23(2.3-4.5)$ & $0.68(0.6-0.8)$ \\
$>5.2$ & $42.36(34.2-50.9)$ & $78.83(75.3-82.0)$ & $3.52(2.2-5.7)$ & $0.73(0.6-0.8)$ \\
$>5.3$ & $33.33(25.7-41.7)$ & $89.67(86.9-92.0)$ & $5.65(2.9-11.0)$ & $0.74(0.7-0.8)$ \\
$>5.4$ & $18.75(12.7-26.1)$ & $94.67(92.6-96.3)$ & $6.55(2.6-16.6)$ & $0.86(0.8-0.9)$ \\
$>5.5$ & $13.19(8.1-19.8)$ & $97.67(96.1-98.7)$ & $8.33(2.1-32.9)$ & $0.89(0.8-0.9)$ \\
$>5.6$ & $7.64(3.9-13.3)$ & $98.83(97.6-99.5)$ & $8.33(1.5-45.1)$ & $0.93(0.9-1.0)$ \\
$>5.7$ & $4.17(1.5-8.8)$ & $99.5(98.5-99.9)$ & $16.67(1.9-148.0)$ & $0.96(0.9-1.0)$ \\
$>5.8$ & $2.78(0.8-7.0)$ & $99.67(98.8-100.0)$ & $8.33(0.8-91.3)$ & $0.98(0.9-1.0)$ \\
$>5.9$ & $2.78(0.8-7.0)$ & $99.83(99.1-100.0)$ & $0.97(0.9-1.0)$ \\
$>6$ & $1.39(0.2-4.9)$ & $99.83(99.1-100.0)$ & $0.99(1.0-1.0)$ \\
$>6.1$ & $0(0.0-2.5)$ & $100(99.4-100.0)$ & $1(1.0-1.0)$ \\
\hline
\end{tabular}

Note: NLR: likelihood ratio; PLR: positive likelihood ratio.

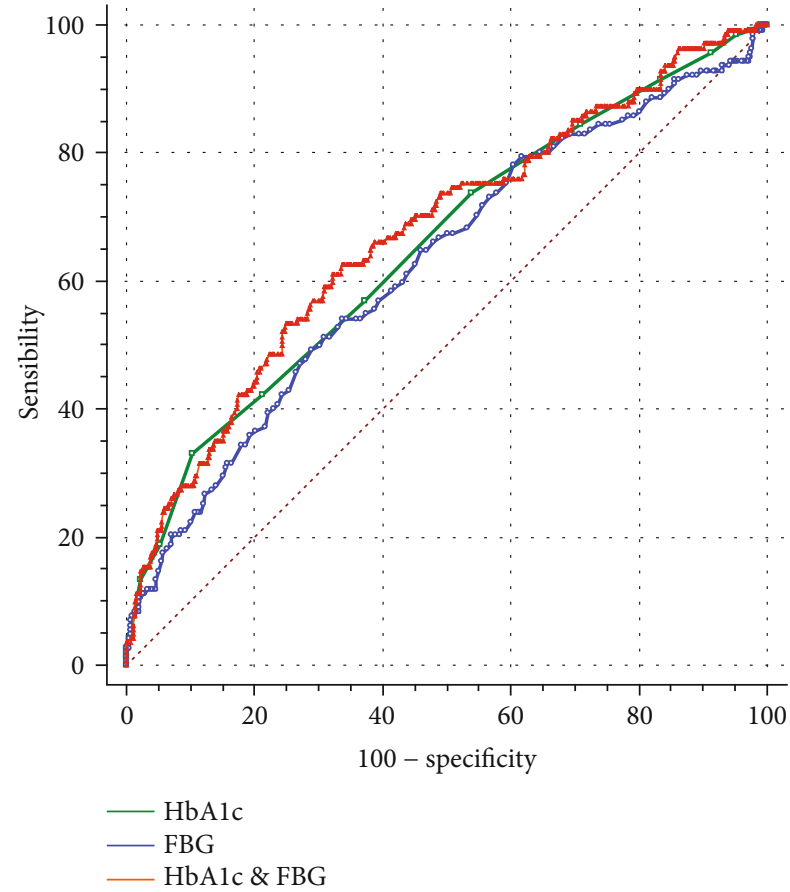

FIGURE 2: Comparison of the ROC curves of HbAlc, FBG, and the two combined indexes.

[17]. The results of the Hyperglycemia and Adverse Pregnancy Outcome study showed that maternal blood glucose levels were continuously associated with increased birth weight, increased cord blood serum C-peptide levels, and perinatal complications, without corresponding blood glu- cose turning points [14]. Lifestyle interventions before 20 weeks' gestation in pregnant women at high risk of GDM can reduce the complications of GDM [18]. Therefore, early identification and active management of labor are particularly important in reducing the adverse outcomes of GDM.

Early predictors of GDM include blood glucose indicators, inflammatory markers, insulin resistance indicators, and adipocyte factors [19]; however, the latter has not been widely used in clinical practice. Blood glucose and glycosylated hemoglobin are the most commonly used indicators in clinical practice. The American College of Obstetricians and Gynecologists (ACOG) recommends a two-step GDM screening beginning with the $50 \mathrm{~g}$ oral glucose challenge test (OGCT), whereas the ADA recommends $75 \mathrm{~g}$ OGTT onestep or two-step screening for GDM [20]. A $50 \mathrm{~g}$ OGCT can also be used to predict delivery weight for gestational age $[21,22]$. HbA1c reflects the three-month average blood glucose level, which has low individual variability and cannot be affected by time, diet, emotion, and stress responses. However, HbAlc is not recommended for the diagnosis of GDM. This study was aimed at exploring the predictive value of first-trimester HbA1c levels in patients with GDM. Although some studies have discussed the relationship between HbAlc and GDM in early pregnancy, most of these have used the two-step method as the diagnostic standard for GDM $[23,24]$. In this study, a one-step method was used as the gold standard for diagnosing GDM. This study found that first-trimester HbAlc levels can be used to predict the occurrence of GDM.

This study showed that the prevalence of GDM was $19.4 \%$ and identified maternal age and BMI as risk factors for GDM. With each 1-year increase in age, the risk of 
GDM increased by $7.5 \%$. Furthermore, the results of this study showed that the incidence of GDM in primiparous women was significantly lower than that in multiparous women, with a statistically significant difference between the two groups. However, after adjusting for age, it was found that parity was not a risk factor for the occurrence of GDM, which might be related to the older age of multiparous women (33.09 years \pm 3.45 years vs. 29.67 years \pm 3.19 years, $P<0.001)$.

It was also found that the first-trimester $\mathrm{HbAlc} \mathrm{level} \mathrm{was}$ an independent risk factor for GDM. The higher the firsttrimester HbAlc level, the greater the risk of GDM. This finding is consistent with previous research $[23,24]$. The reliability of using first-trimester HbA1c levels to diagnose GDM was statistically significant, with a cutoff point of $5.3 \%$ $(P<0.001)$. O'Shea et al. [25] studied trimester-specific reference intervals for $\mathrm{HbAlc}$ in nondiabetic Caucasian pregnant women and found the normal pregnancy $\mathrm{HbAlc}$-specific reference level to be $4.3 \%-5.4 \%$, which approaches the $5.3 \%$ $\mathrm{HbAlc}$ cutoff point. However, if $5.3 \% \mathrm{HbA} 1 \mathrm{c}$ was used as the diagnostic cutoff point for GDM, the sensitivity was $33.33 \%$. This low sensitivity results in a high rate of missed diagnoses of GDM. Some studies have also shown that the diagnosis of GDM using HbAlc levels in early pregnancy cannot be characterized by both high sensitivity and high specificity $[26,27]$.

Although first-trimester $\mathrm{HbAlc}$ levels cannot be used to diagnose GDM directly, the high specificity of the ROC curve is helpful in predicting the occurrence of GDM. On the basis of this study, the positive likelihood ratio was highest at 5.9\% $\mathrm{HbAlc}$ in the first trimester, and the sensitivity and specificity of GDM diagnosis were $2.78 \%$ and $99.83 \%$, respectively, as shown in Table 3 . This indicates that the rate of false diagnosis of GDM was very low in pregnant women with $\mathrm{HbAl}$ c $>5.9 \%$. For these women, GDM can be diagnosed in the first trimester without waiting for an OGTT in the second trimester. In Indian pregnant women, $\mathrm{HbAlc} \geq 5.9 \%$ as the diagnostic cutoff point also showed a low sensitivity of $1.19 \%$ and a high specificity of $99.76 \%[26]$. HbAlc $\geq 5.9 \%$ in early pregnancy is associated with an increased risk of adverse pregnancy outcomes $[28,29]$. This indicates that lifestyle interventions for pregnant women with first-trimester $\mathrm{HbAlclevels}>5.9 \%$ must be implemented as early as possible to reduce the likelihood of adverse pregnancy outcomes.

In this study, the negative likelihood ratio was the lowest at $4.4 \%$, with sensitivity and specificity of $100 \%$ and $1.67 \%$, respectively. This indicates that the risk of GDM at $\mathrm{HbAlc}$ $<4.4 \%$ was extremely low, and GDM can be excluded in pregnant women with first-trimester $\mathrm{HbAlc}<4.4 \%$. Nevertheless, this study showed that OGTT is still recommended for screening for gestational diabetes in pregnant women with $\mathrm{HbAlc}$ between $4.4 \%$ and $5.9 \%$.

The results of this study showed that the AUC of HbA1c levels did not better predict GDM than did FBG levels and that the combination of FBG and HbAlc levels did not improve the AUC. This may be related to the pathophysiological mechanisms of GDM. The occurrence of GDM is affected by various factors. In contrast to the pathogenesis of diabetes, gestational diabetes is closely related to endocrine function, substance metabolism, and the transport function of the placenta [30]. In this study, HbA1c reflects blood glucose levels before pregnancy and during first-trimester pregnancy, when placental function is still immature. For this reason, the sensitivity of $\mathrm{HbAlc}$ in predicting GDM is poor.

This study is a self-sequenced longitudinal prospective study focusing on first-trimester HbAlc levels in China. This study has some limitations. First, $\mathrm{HbAlc}$ is associated with ethnicity, and therefore, this study is only representative of eastern Asian pregnant women. Second, the influence of genetic factors and a family history of diabetes on the development of GDM in the research participants is not reflected in this study, as records of family history of diabetes were not available.

\section{Conclusions}

In conclusion, first-trimester $\mathrm{HbAlc}$ levels show low sensitivity and high specificity in the diagnosis of GDM and thus have limited value in diagnosing GDM. However, HbAlc levels show good predictive value for GDM. GDM can be excluded in pregnant women with first-trimester $\mathrm{HbAlc}$ levels $<4.4 \%$. However, the risk of GDM increases significantly in pregnant women with first-trimester $\mathrm{HbAlc}$ levels $>5.9 \%$. Pregnant women with a first-trimester $\mathrm{HbA}$ 1clevel $>5.9 \%$ should be referred for lifestyle interventions in the first trimester to reduce the risk of developing GDM later in pregnancy.

\section{Data Availability}

The data used to support the findings of this study are available from the corresponding author upon request.

\section{Conflicts of Interest}

The authors declare that there are no conflicts of interest.

\section{Acknowledgments}

This study was supported by the Capital Featured Clinical Application Research Project (Z171100001017126) and the key project of the Peking University International Hospital Fund (YN2016ZD01).

\section{References}

[1] World Health Organization, "Diagnostic criteria and classification of hyperglycaemia first detected in pregnancy: a World Health Organization guideline," Diabetes Research and Clinical Practice, vol. 103, no. 3, pp. 341-363, 2014.

[2] A. L. Fedullo, A. Schiattarella, M. Morlando et al., "Mediterranean diet for the prevention of gestational diabetes in the Covid-19 era: implications of Il-6 in diabesity," International Journal of Molecular Sciences, vol. 22, no. 3, p. 1213, 2021.

[3] L. Ghesquière, C. Garabedian, E. Drumez et al., "Effects of COVID-19 pandemic lockdown on gestational diabetes mellitus: a retrospective study," Diabetes \& Metabolism, vol. 47, no. 2 , article 101201, 2021. 
[4] American College of Obstetricians and Gynecologists, Practice Bulletin, "ACOG practice bulletin no. 190: gestational diabetes mellitus,” Obstetrics \& Gynecology, vol. 131, no. 2, pp. e49-e64, 2018.

[5] P. Damm, "Future risk of diabetes in mother and child after gestational diabetes mellitus," International Journal of Gynaecology and Obstetrics, vol. 104, Supplement 1, pp. S25-S26, 2009.

[6] E. Vounzoulaki, K. Khunti, S. C. Abner, B. K. Tan, M. J. Davies, and C. L. Gillies, "Progression to type 2 diabetes in women with a known history of gestational diabetes: systematic review and meta-analysis," BMJ: British Medical Journal, vol. 369, 2020.

[7] B. Baz, J. P. Riveline, and J. F. Gautier, "Endocrinology of pregnancy: gestational diabetes mellitus: definition, aetiological and clinical aspects," European Journal Of Endocrinology, vol. 174, no. 2, pp. R43-R51, 2016.

[8] L. Mañé, J. A. Flores-le Roux, N. Gómez et al., “Association of first-trimester HbA1c levels with adverse pregnancy outcomes in different ethnic groups," Diabetes Research and Clinical Practice, vol. 150, pp. 202-210, 2019.

[9] D. Benaiges, J. A. Flores-le Roux, I. Marcelo et al., "Is firsttrimester HbAlc useful in the diagnosis of gestational diabetes?," Diabetes Research and Clinical Practice, vol. 133, pp. 85-91, 2017.

[10] L. R. Nielsen, P. Ekbom, P. Damm et al., "HbA1c levels are significantly lower in early and late pregnancy," Diabetes Care, vol. 27, no. 5, pp. 1200-1201, 2004.

[11] International Association of Diabetes and Pregnancy Study Groups Consensus Panel, B. E. Metzger, S. G. Gabbe et al., "International association of diabetes and pregnancy study groups recommendations on the diagnosis and classification of hyperglycemia in pregnancy," Diabetes Care, vol. 33, no. 3, pp. 676-682, 2010.

[12] American Diabetes Association, "Standards of medical care in diabetes-2012," Diabetes Care, vol. 35, Supplement 1, pp. S11S63, 2012.

[13] Obstetrics Subgroup, Chinese Society of Obstetrics and Gynecology, Chinese Medical Association; Group of Pregnancy with Diabetes Mellitus, and Chinese Society of Perinatal Medicine, Chinese Medical Association, "Diagnosis and therapy guideline of pregnancy with diabetes mellitus (2014)," Chinese Journal of Obstetrics and gynecology, vol. 49, pp. 561-569, 2014.

[14] HAPO Study Cooperative Research Group, B. E. Metzger, L. P. Lowe et al., "Hyperglycemia and adverse pregnancy outcomes," The New England Journal of Medicine, vol. 358, no. 19, pp. 1991-2002, 2008.

[15] E. M. Wendland, M. R. Torloni, M. Falavigna et al., "Gestational diabetes and pregnancy outcomes-a systematic review of the World Health Organization (WHO) and the International Association of Diabetes in Pregnancy Study Groups (IADPSG) diagnostic criteria," BMC Pregnancy Childbirth, vol. 12, no. 1, 2012.

[16] D. Vitner, L. Hiersch, E. Ashwal, A. Shmueli, Y. Yogev, and A. Aviram, "Induction of labor versus expectant management for gestational diabetes mellitus at term," Archives Of Gynecology And Obstetrics, vol. 300, no. 1, pp. 79-86, 2019.

[17] P. Damm, A. Houshmand-Oeregaard, L. Kelstrup, J. Lauenborg, E. R. Mathiesen, and T. D. Clausen, "Gestational diabetes mellitus and long-term consequences for mother and offspring: a view from Denmark," Diabetologia, vol. 59, no. 7, pp. 1396-1399, 2016.

[18] N. Maher, F. McAuliffe, and M. Foley, "The benefit of early treatment without rescreening in women with a history of gestational diabetes," The Journal of Maternal-Fetal \& Neonatal Medicine, vol. 26, no. 3, pp. 318-320, 2013.

[19] C. E. Powe, "Early pregnancy biochemical predictors of gestational diabetes mellitus," Current Diabetes Reports, vol. 17, no. 2, p. 12, 2017.

[20] L. R. Mack and P. G. Tomich, "Gestational diabetes: diagnosis, classification, and clinical care," Obstetrics and Gynecology Clinics of North America, vol. 44, no. 2, pp. 207-217, 2017.

[21] A. Tanacan, M. Eyupoglu, E. Fadiloglu, H. Y. Zengin, E. Karaagaoglu, and M. S. Beksac, "Use of the 50-g glucose challenge test to predict small-for-gestational-age neonates," Journal of Diabetes, vol. 12, no. 11, pp. 791-797, 2020.

[22] M. S. Beksac, A. Tanacan, D. A. Hakli, and O. Ozyuncu, "Use of the 50-g glucose challenge test to predict excess delivery weight," International Journal of Gynaecology and Obstetrics, vol. 142, no. 1, pp. 61-65, 2018.

[23] S. N. Hinkle, M. Y. Tsai, S. Rawal, P. S. Albert, and C. Zhang, "HbA1c measured in the first trimester of pregnancy and the association with gestational diabetes," Scientific Reports, vol. 8, no. 1, article 12249, 2018.

[24] A. Fong, A. E. Serra, L. Gabby, D. A. Wing, and K. M. Berkowitz, "Use of hemoglobin A1c as an early predictor of gestational diabetes mellitus," American Journal Of Obstetrics And Gynecology, vol. 211, no. 6, pp. 641.e1-641.e7, 2014.

[25] P. O'Shea, C. O'Connor, L. Owens et al., "Trimester-specific reference intervals for IFCC standardised haemoglobin A (1c): new criterion to diagnose gestational diabetes mellitus (GDM)?," Irish Medical Journal, vol. 105, 5 Supplement, pp. 29-31, 2012.

[26] J. Punnose, R. K. Malhotra, K. Sukhija, A. Mathew, A. Sharma, and N. Choudhary, "Glycated haemoglobin in the first trimester: a predictor of gestational diabetes mellitus in pregnant Asian Indian women," Diabetes Research and Clinical Practice, vol. 159, article 107953, 2020.

[27] S. Amylidi, B. Mosimann, C. Stettler, G. M. Fiedler, D. Surbek, and L. Raio, "First-trimester glycosylated hemoglobin in women at high risk for gestational diabetes," Acta Obstetricia et Gynecologica Scandinavica, vol. 95, no. 1, pp. 93-97, 2016.

[28] R. C. Hughes, M. P. Moore, J. E. Gullam, K. Mohamed, and J. Rowan, "An early pregnancy HbAlc $\geq 5.9 \%$ (41 $\mathrm{mmol} / \mathrm{mol})$ is optimal for detecting diabetes and identifies women at increased risk of adverse pregnancy outcomes," DIABETES CARE, vol. 37, no. 11, pp. 2953-2959, 2014.

[29] A. N. Sweeting, G. P. Ross, J. Hyett et al., "Baseline HbA1c to identify High Risk gestational diabetes: utility in early Versus standard gestational diabetes," The Journal of Clinical Endocrinology and Metabolism, vol. 102, pp. jc.2016-jc.2951, 2017.

[30] J. F. Plows, J. L. Stanley, P. N. Baker, C. M. Reynolds, and M. H. Vickers, "The pathophysiology of gestational diabetes mellitus," International Journal Of Molecular Sciences, vol. 19, no. 11 , p. $3342,2018$. 